\title{
Diagnostic and therapeutic peroral cholangioscopy
}

\author{
Jong Ho Moon, Yu Ri Seo, Hyun Jong Choi
}

Digestive Disease Center, Department of Internal Medicine, Soon Chun Hyang University School of Medicine, Bucheon/Seoul, Korea

\begin{abstract}
Peroral cholangioscopy (POC) provides direct visualization of the bile duct and facilitates diagnostic or therapeutic intervention. The currently available single-operator POC systems are "Mother-baby" scope system, SpyGlass direct visualization system, and direct POC using a regular ultra-slim upper endoscope. Direct POC using an ultra-slim upper endoscope having a larger 2-mm working channel can provide a valuable and economic solution for evaluating bile-duct lesions. Main diagnostic procedures under direct POC are visual characterization and optically guided target biopsy for the indeterminate bile duct lesion. Image-enhanced endoscopy such as narrow-band imaging has shown promise for more detailed evaluation of mucosal abnormality and can be performed under direct POC. Intracorporeal lithotripsy such as electrohydraulic lithotripsy or laser lithotripsy is a main therapeutic intervention of direct POC for patients with bile duct stones that are resistant to conventional endoscopic stone-removal procedures. Besides, tumor ablation therapy, such as photodynamic therapy and argon plasma coagulation may be also performed using direct POC. Further developments of the endoscope and specialized accessories or devices are expected to facilitate diagnostic and therapeutic role of this cholangioscopic procedure.

Key words Peroral cholangioscopy, ultra-slim endoscope, spyglass, narrow-band imaging, lithotripsy, tumor ablation
\end{abstract}

\section{Introduction}

Cholangioscopy permits direct visualization of the biliary tree for diagnostic procedures and provides endoscopic guidance for therapeutic interventions. ${ }^{[1]}$ Peroral cholangioscopy (POC) can be performed using a mother-baby endoscopic system, but this procedure is difficult, time-consuming, and requires the presence of two skilled endoscopists. A small-caliber baby scope is easily broken, expensive, and difficult for interventional procedures, with small working channel having $1.2 \mathrm{~mm}$ diameter. These problems have hindered widespread use of POC and the role of this technique has been remained limited.

\section{Access this article online}

\section{Website:}

www.jdeonline.in

DOI:

10.4103/0976-5042.95026
Recently, there have been remarkable developments in this technology to regain interest in cholangioscopy. Direct POC using a regular ultra-slim upper endoscope has been proposed as one of single operator systems for the direct endoscopic examination of the biliary tree. ${ }^{[2]}$ The advantage of direct POC using an ultra-slim endoscope is conduction by conventional endoscopy equipment and set-up, the superior image quality for biliary tree, and operation by single endoscopist. Furthermore, because an ultra-slim endoscope has a larger 2-mm working channel, it can facilitate the diagnostic and therapeutic procedures by a broader array of devices in patients with various biliary diseases and conditions.

\section{Direct POC Systems Using an Ultra-slim Upper Endoscope}

The usual outer diameter of an ultra-slim upper endoscope is 5-6 mm. In order to perform direct POC, ductal access is prepared and cholangiography undertaken at the time of Endoscopic retrograde cholangiopancreatography (ERCP). Patients with a grossly dilated common bile duct (CBD) having 
adequately opened ampullary orifice are suitable for direct POC using slim endoscope. The major obstacle for direct POC using an ultra-slim endoscope is the relatively acute angle that must be maneuvered from the second part of the duodenal lumen into the biliary system. Therefore, specialized accessories or techniques are necessary to advance ultra-slim endoscopes into the proximal biliary system and to improve the success rate of direct POC. ${ }^{[2]}$

We reported an innovative technique using direct POC with an intraductal 5-F balloon catheter which can be anchored and fixed via ballooning within a branch of the intrahepatic ducts (IHD) or proximal portion of strictured segment [Figure 1]. ${ }^{[3]}$ This method showed high success rate (95.2\%). Overtube balloon-assisted direct POC may be useful to perform therapeutic intervention with instruments. ${ }^{[4]}$

\section{Diagnostic Procedures under Direct POC}

\section{Visual characterization and optically guided target biopsy of biliary lesion}

Cholangioscopy provides advantages over ERCP in the diagnosis of lesions in the bile duct by direct visualization of the biliary tree [Figure 2], and accordingly can detect irregular surface features of the bile duct wall and visualize the vascular pattern that characterizes malignancy. Optical visual information discloses characteristics of filling defects or stricture site, which enables us not only to differentiate between benign and malignant strictures, but also to apply treatment or to biopsy [Figure 3] ${ }^{[5]}$ Continued progress in imaging technology has led to further enhancement in the image resolution of video cholangioscopes. ${ }^{[6]}$ Recently developed SpyGlass POC system also showed a high accuracy in confirming or excluding malignancy in patients with indeterminate biliary lesions. ${ }^{[7,8]}$ Direct POC using an ultra-slim endoscope offers superior image quality of the ductal mucosa, and the separator water and air channels improve intraductal visualization and the $2.0-\mathrm{mm}$ working channel allows the passage of larger biopsy forceps, which may increase the diagnostic yield during tissue sampling. ${ }^{[3]}$

\section{Image-enhanced cholangioscopy}

Narrow-band imaging (NBI) can be helpful for detecting early neoplasia in the gastrointestinal tract due to its ability to yield clear images of the surface structure and microvessels. Also, it is easily applicable during direct POC [Figure 4]. Itoi et al. ${ }^{\left[{ }^{90}\right.}$ reported the usefulness of NBI for the diagnosis of biliary disease using POC, which may increase the detectability of biliary tract disease, even of minute lesions. We reported a case of early bile duct cancer diagnosed at direct POC with NBI using an ultra-slim endoscope. ${ }^{[10]}$ As bile is seen as red, even a small amount of bile lowers the observation performance. Therefore, bile aspiration and sufficient washing with physiological saline are necessary, and compared to conventional endoscopy, caution must be exercised regarding complications of ascending cholangitis. NBI cholangioscopy is

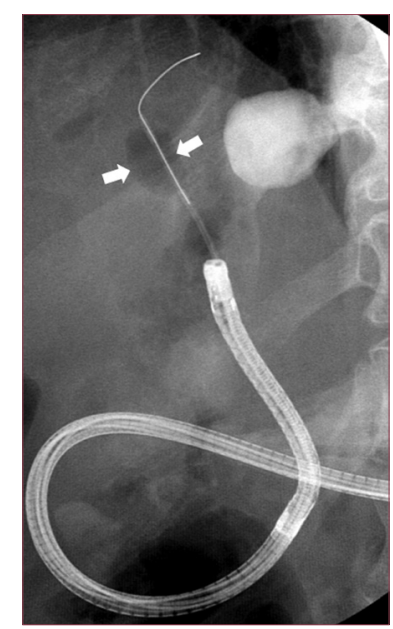

Figure 1: Radiograph demonstrating intraductal balloon-guided direct peroral cholangioscopy (POC) (arrows indicate the balloon)

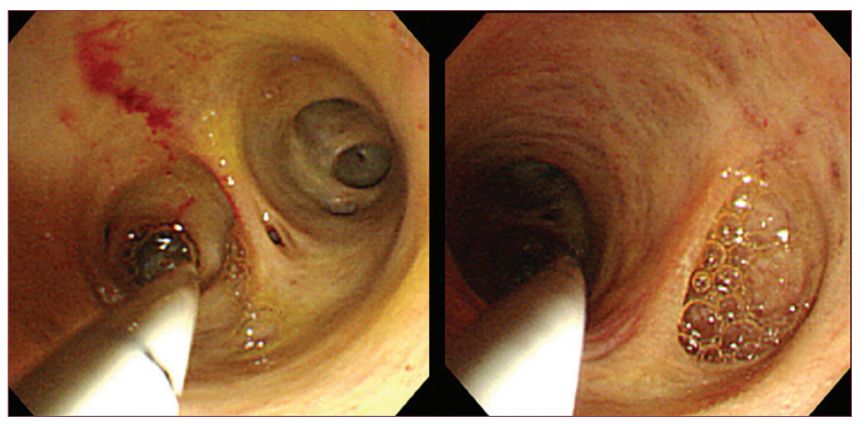

Figure 2: Cholangioscopic view showing normal bile duct

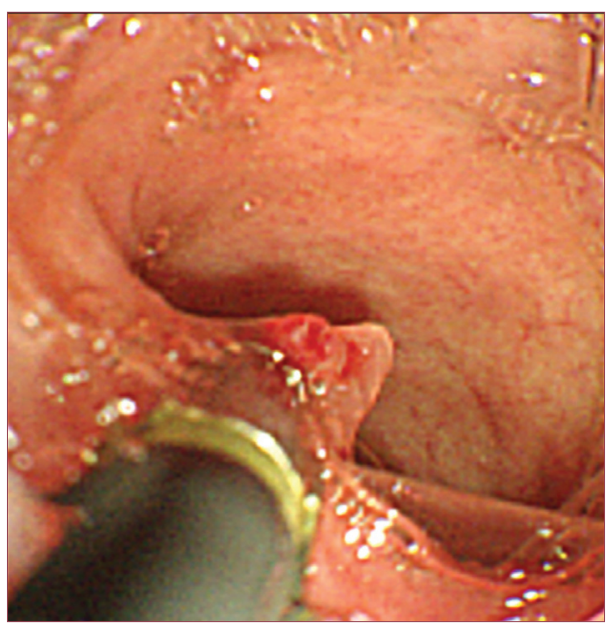

Figure 3: Cholangioscopic view showing optical-guided target biopsy for intraductal polypoid lesion

expected to make it possible to detect not only polypoid lesions but also flat superficial cancerous lesions..$^{[9]}$

Miscellaneous diagnostic applications of direct POC Itoi et al. ${ }^{[1]}$ evaluated the usefulness of POC for residual bile duct stones in patients with complete bile duct clearance confirmed by balloon-occluded cholangiography. In 26 patients (24\%), residual stones were detected using POC, but missed at 
balloon-occluded cholangiography. They suggested that POC appears to be a useful diagnostic tool to confirm complete extraction of bile duct stones.

In addition, direct $\mathrm{POC}$ appears to be useful for visual evaluation of intraductal spread of ampullary adenoma, choledochal cyst, and ductal ischemia after liver transplantation.

\section{Therapeutic Procedures under Direct POC}

\section{Endoscopic intraductal lithotripsy for difficult bile duct stones}

POC with intracorporeal lithotripsy, such as electrohydraulic lithotripsy (EHL) and laser lithotripsy (LL), achieves complete clearance of difficult extrahepatic biliary stones in $83-100 \%$ of patients [Figure 5]. ${ }^{[12-14]}$ SpyGlass POC system and direct POC using an ultra-slim endoscope also were reported as effective and safe modalities in patients with difficult-to-extract CBD stones. ${ }^{[7,15]}$ During POC for intraductal lithotripsy, a separate drainage tube is needed in the presence of a lithotripsy probe or fiber within the working channel for continuous irrigation with a mixed infusion of contrast medium and saline solution for the effective lithotripsy, cleansing, and identification of fragmented stones.

\section{Endoscopic intraductal tumor ablation therapy}

The 2.0-mm working channel of the slim endoscope for direct POC could facilitate the application of therapies for malignancies. Cholangioscopy-directed photodynamic therapy (PDT) for nonresectable cholangiocarcinoma has been reported. ${ }^{[16,17]}$ Treatment with PDT and stenting also led to improvement of cholestasis and quality of life compared with endoscopic stenting alone. Application of PDT under direct POC may be effective and well controlled by endoscopic guidance. Endoscopic examination with direct POC is also important to estimate the effectiveness, remnant cancerous tissue, or the recurrence. Siddique et al. ${ }^{[18]}$ reported Nd-YAG laser ablation of tumor stent ingrowth and biliary angiodysplastic lesions under POC. Argon plasma coagulation (APC) has a role in tumor ablation with desiccation and necrosis of the superficial tissue. Park et al ${ }^{[19]}$ described direct POC using an ultra-slim upper endoscope for recurrent icteric-type hepatoma. Brauer et al. ${ }^{[20]}$ performed direct cholangioscopic APC using a conventional thin gastroscope for the ablation of a biliary intraductal papillary mucinous neoplasm.

\section{Miscellaneous therapeutic applications of direct POC}

There are other therapeutic interventions which have been coupled with direct POC. Cholangioscopy has been used to achieve selective guidewire access to the cystic and intrahepatic ducts, and in stricture management. ${ }^{[21,22]}$ Direct POC also allows the insertion of a guidewire into tortuous, complicated bile duct strictures for subsequent balloon dilatation.

Stent migration occurs in $5-10 \%$ of biliary stenting patients. $70-90 \%$ of proximally migrated stents are successfully

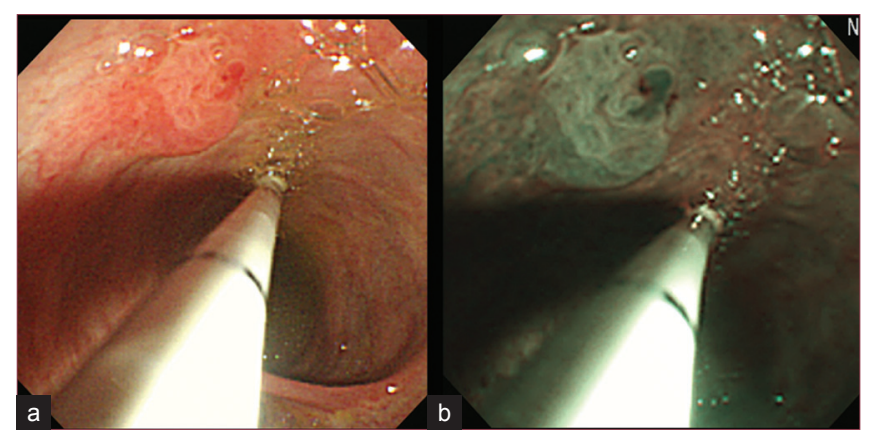

Figure 4: Cholangioscopic view showing intraductal polypoid lesion. (a) White light imaging (b) Narrow-band imaging

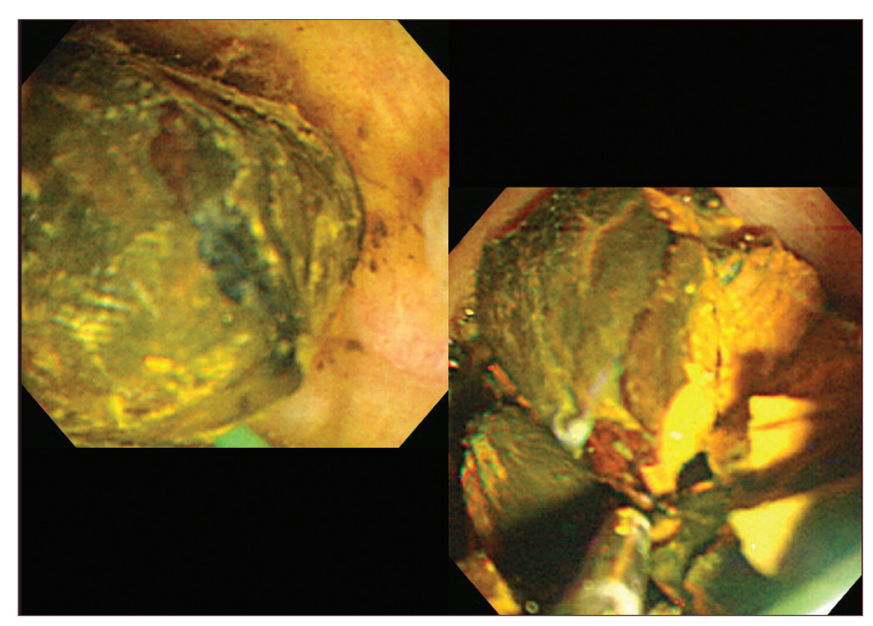

Figure 5: Cholangioscopic view showing direct peroral cholangioscopyguided electrohydraulic lithotripsy

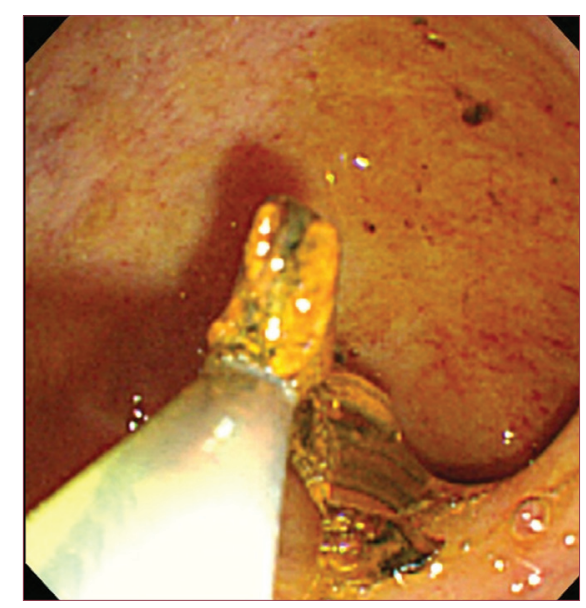

Figure 6: Cholangioscopic view showing removal of remnant stones under direct peroral cholangioscopy

retrieved by conventional endoscopic procedures. ${ }^{[23]}$ Other patients require additional procedures for stent removal. Direct POC system can be used to removal of proximally migrated biliary stent under direct visual examination [Figure 6].

\section{Conclusion}

Several recent developments including direct POC control using 
an ultra-slim upper endoscope are changing the limitations of current cholangioscopy system. Direct intraductal visualization with image-enhanced cholangioscopy and target biopsy can provide decisive clues for intraductal biliary lesions. Intraductal lithotripsy with EHL or LL, and tumor ablation with PDT or APC under direct POC is a feasible, successful, and safe procedure for patients with biliary tract disease that is not amenable to conventional endoscopy. In addition, the continuous development of specialized endoscopes and accessories is needed to improve the therapeutic application of POC to biliary diseases.

\section{References}

1. Neuhaus H. Cholangioscopy. Endoscopy 1992;24:125-32.

2. Larghi A, Waxman I. Endoscopic direct cholangioscopy by using an ultra-slim upper endoscope: A feasibility study. Gastrointest Endosc 2006;63:853-7.

3. Moon JH, Ko BM, Choi HJ, Hong SJ, Cheon YK, Cho YD, et al. Intraductal balloon-guided direct peroral cholangioscopy with an ultraslim upper endoscope (with videos). Gastrointest Endosc 2009;70:297-302.

4. Choi HJ, Moon JH, Ko BM, Hong SJ, Koo HC, Cheon YK, et al. Overtube-balloon-assisted direct peroral cholangioscopy by using an ultra-slim upper endoscope (with videos). Gastrointest Endosc 2009;69:935-40.

5. Shim CS, Neuhaus H, Tamada K. Direct cholangioscopy. Endoscopy 2003;35:752-8.

6. Itoi T, Osanai M, Igarashi $\mathrm{Y}$, Tanaka K, Kida M, Maguchi H, Yasuda K, et al. Diagnostic peroral video cholangioscopy is an accurate diagnostic tool for patients with bile duct lesions. Clin Gastroenterol Hepatol 2010;8:934-8.

7. Chen YK, Parsi MA, Binmoeller KF, Hawes RH, Pleskow DK, Slivka A, et al. Single-operator cholangioscopy in patients requiring evaluation of bile duct disease or therapy of biliary stones (with videos). Gastrointest Endosc 2011;74:805-14.

8. Ramchandani M, Reddy DN, Gupta R, Lakhtakia S, Tandan M, Darisetty $\mathrm{S}$, et al. Role of single-operator peroral cholangioscopy in the diagnosis of indeterminate biliary lesions: A single-center, prospective study. Gastrointest Endosc 2011;74:511-9.

9. Itoi T, Sofuni A, Itokawa F, Tsuchiya T, Kurihara T, Ishii K, et al. Peroral cholangioscopic diagnosis of biliary-tract diseases by using narrow-band imaging (with videos). Gastrointest Endosc 2007;66:730-6.

10. Kim HK, Moon JH, Choi HJ, Kim HK, Min SK, Park JK, et al. Early bile duct cancer detected by direct peroral cholangioscopy with narrow-band imaging after bile duct stone removal. Gut Liver 2011;5:377-9.

11. Itoi T, Sofuni A, Itokawa F, Shinohara Y, Moriyasu F, Tsuchida A. Evaluation of residual bile duct stones by peroral cholangioscopy in comparison with balloon-cholangiography. Dig Endosc 2010;22 Suppl 1: S85-9.

12. Arya N, Nelles SE, Haber GB, Kim YI, Kortan PK. Electrohydraulic lithotripsy in 111 patients: A safe and effective therapy for difficult bile duct stones. Am J Gastroenterol 2004;99:2330-4.

13. Piraka C, Shah RJ, Awadallah NS, Langer DA, Chen YK. Transpapillary cholangioscopy-directed lithotripsy in patients with difficult bile duct stones. Clin Gastroenterol Hepatol 2007;5:1333-8.

14. Farrell JJ, Bounds BC, Al-Shalabi S, Jacobson BC, Brugge WR, Schapiro RH, et al. Single-operator duodenoscope-assisted cholangioscopy is an effective alternative in the management of choledocholithiasis not removed by conventional methods, including mechanical lithotripsy. Endoscopy 2005;37:542-47.

15. Moon JH, Ko BM, Choi HJ, Koo HC, Hong SJ, Cheon YK, et al. Direct peroral cholangioscopy using an ultra-slim upper endoscope for the treatment of retained bile duct stones. Am J Gastroenterol 2009;104:2729-33.

16. Shim CS, Cheon YK, Cha SW, Bhandari S, Moon JH, Cho YD, et al. Prospective study of the effectiveness of percutaneous transhepatic photodynamic therapy for advanced bile duct cancer and the role of intraductal ultrasonography in response assessment. Endoscopy 2005;37:425-33.

17. Choi HJ, Moon JH, Ko BM, Min SK, Song AR, Lee TH, et al. Clinical feasibility of direct peroral cholangioscopy-guided photodynamic therapy for inoperable cholangiocarcinoma performed by using an ultra-slim upper endoscope (with videos). Gastrointest Endosc 2011;73:808-13.

18. Siddique I, Galati J, Ankoma-Sey V, Wood RP, Ozaki C, Monsour H, et al. The role of choledochoscopy in the diagnosis and management of biliary tract diseases. Gastrointest Endosc 1999;50:67-73.

19. Park do H, Park BW, Lee HS, Park SH, Park JH, Lee SH, et al. Peroral direct cholangioscopic argon plasma coagulation by using an ultraslim upper endoscope for recurrent hepatoma with intraductal nodular tumor growth (with videos). Gastrointest Endosc 2007;66:201-3.

20. Brauer BC, Fukami N, Chen YK. Direct cholangioscopy with narrow-band imaging, chromoendoscopy, and argon plasma coagulation of intraductal papillary mucinous neoplasm of the bile duct (with videos). Gastrointest Endosc 2008;67:574-6.

21. ASGE Technology Committee, Shah RJ, Adler DG, Conway JD, Diehl DL, Farraye FA, et al. Cholangiopancreatoscopy. Gastrointest Endosc 2008;68:411-21.

22. Wright H, Sharma S, Gurakar A, Sebastian A, Kohli V, Jabbour N. Management of biliary stricture guided by the Spyglass Direct Visualization System in a liver transplant recipient: An innovative approach. Gastrointest Endosc 2008;67:1201-3.

23. Tarnasky PR, Cotton PB, Baillie J, Branch MS, Affronti J, Jowell P, et al. Proximal migration of biliary stents: Attempted endoscopic retrieval in forty-one patients. Gastrointest Endosc 1995;42:513-20.

How to cite this article: Moon JH, Seo YR, Choi HJ. Diagnostic and therapeutic peroral cholangioscopy. J Dig Endosc 2012;3:23-6.

Source of Support: Nil, Conflict of Interest: None declared.

A free application to browse and search the journal's content is now available for iPhone/iPad.

Download iPhone, iPad application
The application provides "Table of Contents" of the latest issues, which are stored on the device for future offline browsing. Internet connection is required to access the back issues and search facility. The application is Compatible with iPhone, iPod touch, and iPad and Requires iOS 3.1 or later. The application can be downloaded from http://itunes.apple.com/us/app/medknow-journals/ $\mathrm{id} 458064375$ ? $\mathrm{s}=1 \& \mathrm{mt}=8$. For suggestions and comments do write back to us. 